\title{
The Reason Behind Female Outnumbering Male Students in Foreign Language High Schools in China
}

\author{
Yin Cheng ${ }^{1, *}, \dagger$, Qianlin $\mathrm{Cui}^{2, \dagger}$, Yujia $\operatorname{Lin}^{3, \dagger}$, Yimo $\mathrm{Zhu}^{4, \dagger}$ \\ ${ }^{1}$ Tianjin Foreign Languages School Affiliated to Tianjin Foreign Studies University \\ ${ }^{2}$ Capital Normal University High School \\ ${ }^{3}$ Hangzhou Foreign Languages School \\ ${ }^{4}$ Hangzhou Foreign Languages School \\ ${ }^{*}$ Corresponding author. Email: guanghua.ren@gecacademy.cn \\ Those authors contributed equally.
}

\begin{abstract}
The foreign language schools in China typically have more female students than male students. To investigate the reason behind this interesting phenomenon, the study took Hangzhou Foreign Languages High School 2022 as an example and interviewed three groups of people (students, parents, society). The total number of subjects is 188 , including 40 students, 8 parents, and 140 subjects of group Society. The interview results indicated that the gender stereotype people hold has a significant impact on female students' choice of attending foreign language schools. Although other reasons such as feminine advantages in brain structure with language function, positive learning strategies, and learning motivation exist, the general social stereotype of girls should study liberal arts subjects and boys should major in natural sciences is one of the major causes of the phenomenon of female students outnumbering male students in Chinese foreign language schools.
\end{abstract}

Keywords: gender difference, gender stereotype, language learning, education

\section{INTRODUCTION}

\subsection{Foreign Language Schools in China}

The Foreign Language Schools in China are special high schools that cultivate international compound talents with foreign language expertise, excellent arts and Sciences, and comprehensive quality [1]. This type of school usually has various foreign language curriculum and courses of global understanding [1].

The origin of the foreign languages schools can be dated to the 1960s. According to prime minister Zhou Enlai, in the context of the establishment of more diplomatic and economic relations between China and other countries, China is in urgent need of a large number of foreign language diplomatic talents [2]. Currently, the foreign languages schools are serving their roles, with 16 of them having prioritized admission qualification [3].

The foreign language schools with foreign language special curriculum attract an unequal amount of female and male students just as the gender difference in college major choices of language, etc.

\subsection{Gender Difference in Major Choices}

Male students tend to study STEM (including sciences, technology, engineering, and mathematics) subjects, while female high school graduates are more likely to major in humanities or social science-related courses [4].

The social expectations, as well as the public role models, have a significant impact on students' choices, leading to segregation in college majors [5]. As what is believed in ancient China, husbands are responsible for outside affairs and wives are responsible for indoor chores [5]. This past perspective has a great impact even now since it is almost rooted in the culture [5]. The males, therefore, would naturally choose more promising majors, given that they know they are at a dominant level in society [5].

For the stereotype that girls are suitable for social science-related courses, some researchers do argue 
about the potential advantage of girls in learning languages.

\subsection{Girls' Advantages in Language Learning}

The brain structure suggests that girls might have the advantage in language learning [6]. Bilateral activation in the lower and upper temporal gyri and activation in the left fusiform gyrus of girls were more significant than in boys [6]. Activation in the left fusiform region was additionally correlated with performance on standardized language tests in which girls performed better, additional evidence of its purpose in early sex differences in language [6].

Another female advantage in language learning is that the girls usually have more positive learning strategies [7]. As with previous researchers, one study has seen greater use of learning strategies among learners who are more successful and higher levels of use of strategies by women than by men [7].

The third possible female advantage lies in language learning motivation. Recent studies have discovered a general relationship between motivation and language learning. The Multivariate Analysis of Variance results show a significant difference in integration by gender, with women achieving much higher outcomes for these elements [8].

For the aforementioned reasons, girls tend to attend foreign language high schools that provide special language programs.

\subsection{Female Students Outnumbering Male Students}

In foreign language high schools in China, there is a general situation that there are more female students than male students. This research specifically looks at Hangzhou Foreign Languages School (HFLS). The study collected the data that 474 of the students enrolled in the 2021-22 academic year are females, which occupies $58.3 \%$, with $60.2 \%$ in grade $10,57.9 \%$ in grade 11 , and $56.0 \%$ in grade 12 . This is relatively high even compared with American top universities: for example, Stanford has only 52\% female in 2024 students [9]. Thus, wondering why this phenomenon of female students outnumbering male students in Foreign Languages Schools exists, this study is to investigate the reasons behind it.

\subsection{Research Statement}

The research investigated the reason behind the observed female students outnumbering male students in foreign languages schools in China. And the study is especially interested in the social expectations different groups of people have, which can impact female students' choices to study at foreign languages schools
[9]. The study expects to find the conclusion that female students outnumber male students in foreign language schools in China because the social expectations and stereotypes push the female students to attend those schools.

\section{METHODS}

\subsection{Subjects}

This study divided the subjects into three groups: students at HFLS, parents at HFLS, subjects in the society unrelated to HFLS. In this research, the researchers interviewed 40 students of HFLS-2022 (31 female students and 9 male students), 8 parents of HFLS-2022 ( 4 parents of female students and 4 parents of male students), and 140 subjects from the Society group not having any relationships with HFLS (117 females and 23 males), this group mainly from the city Tianjin in China.

\subsection{Questionnaires}

The students were asked questions from the basic male or female to the more in-depth ones. There are in total 6 questions. All of them are open questions without correct answers. It approximately takes students 5 minutes to complete. The questions for students include why they chose HFLS and if the decision is affected by their parents, what combination of courses did the students select, what careers do they think are suitable for girls, and their future career planning as well as whether if it is supported by their parents.

The group of parents is also asked from the basic to questions more about their attitudes. There are in total 5 questions. All of them are open questions without correct answers. It approximately takes parents 5 minutes to complete. The questionnaire has questions of reasons the parents supported their child to attend HFLS, advantages of girls and boys respectively in learning in their mind, careers suitable for girls in their opinion, and if they have discussed the future career with their child and whether they reached the consensus. For the careers suitable for girls, both listed in the questionnaire of the Students and Parents, the questionnaire gives the example of no particular preference/ econ business/law/medicine/ scientific research/ journalism publication/ Information Technology for the subjects to reference.

For the third group, Society, a multiple-choice-based questionnaire is designed to help the study to find the general opinion of the public. There are in total 5 questions. 4 of them are multiple-choice questions; within the 4 multiple-choice questions, 2 of the questions allow subjects to choose more than one option. The last question is an open question without a definite answer. It approximately takes subjects 5 minutes to 
complete. Simple questions are listed at the beginning such as the gender and age of the subjects. And as the Students and Parents have been asked, the subjects of Society are also required to choose a suitable career for girls from the option of no particular preference/ econ business/law/medicine/ scientific research/ journalism publication/ Information Technology. In addition, this group of people is required to choose one word that they think can describe females best from attentive/ emotional/ rational/ introvert/ extroverted/ composed/ leadership.

\subsection{Procedures}

This study conducted interviews with three groups of subjects respectively. The interviews for the Students and Parents groups include questionnaires with no multiple-choice questions but open questions that do not have a definite correct answer. For these two groups, the team interviewed the subjects offline face to face. The interview questionnaire for the group of Society has mainly multiple-choice questions. For the Society groups, the interview is completed online. The questionnaires are designed to be objective with no indication of the research theme of gender difference to influence the subjects' answers. The interviews for students took place at HFLS in September 2021. The interviews for parents and the group Society were online in September 2021.

\subsection{Statistical Methods}

For the interview of the Students and Parents groups, the data analysis is relatively complicated compared to the Society group where a simple statistical method is used to deal with multiple-choice questions. After collecting the answers to the questionnaire, the team had to read through all the open question paragraphs and categorize them according to individual answers. The study also reviewed all the opinions of Students and Parents to conclude typical views each group holds. For the multiple-choice questionnaire for the Society, the study needs to count the number of supporters for each choice and compare them.

\section{RESULT AND DISCUSSION}

\subsection{Result}

As for the subject of Students, a total of 40 responses are collected through questionnaires, thirty-one of which are from female students and nine are from male students in Hangzhou Foreign Languages School (HFLS). For the question of selection of courses combination, there are 20 out of 31 students, $64.52 \%$ of the total students chose Politics, a liberal arts subject that requires a lot of remembering, as their Gaokao subject. On contrary, there are only 7 female students who chose physics, a science subject that needs students to understand the formulas and requires strong logical thinking. This shows that when coming with subject choices, the majority of female students tended to avoid choosing subjects that require higher logic and understanding ability. For the question of students' future career planning, the majority of students tended to predict that more women would like to enter the field of liberal arts or business. $45 \%$ of students think women will do jobs related to arts and business, and fewer people think they will find employment in the sciences field. Another finding is that there is a large number of students mentioned the opinion of the "same possibility" in the question asking career choices in the questionnaire. They stated that in the new era, neither gender is prior or inferior to the other in chances and abilities.

The interviewee of another group, Parents, include 4 parents of male students and 4 parents of female students. For the question that asks about the learning advantage of girls and boys, 8 out of 8 believe that male students do better on scientific subjects such as mathematics, physics, chemistry, and biology, and female students are better at liberal arts subjects, such as language learning and communication-related curriculum. Among all the options given by the other question, the jobs that are considered to be most suitable for girls chosen by the parents are publication professionals and civil servants. The rate is as high as $82.5 \%$. One of them even directly expressed that females are not suitable for science-related jobs. Also, 5 of the interviewees expressed that they are guiding their female children to develop in the career direction related to social sciences.

For the third group of Society, 141 questionnaire feedbacks are received. When asked about which adjective can be used to describe girls, approximately $40 \%$ of subjects tended to choose adjectives, for example, tentative and emotional, while only around $20 \%$ of them chose the words such as leadership and outgoing. For the question of suitable careers for girls, careers related to the law were most commonly chosen: $31.91 \%$ believed that girls should attend jobs such as lawyer. Only $12.77 \%$ chose areas related to information technology and only $19.86 \%$ of them chose scientific study as suitable future careers.

\subsection{Discussion}

In the interviews with the group Student, the reasons the subjects think women are more likely to enter the field of liberal arts varied. However, all the reasons can be divided into three main types. First, the subjects think females are more attentive and better at perceiving, as supported by the experiments showing that women were faster than men to recognize positive and negative feelings of facial signals [10], making females perform 
better in communication. Second, the subjects believe women are relatively weaker at logic, evidenced by the experiments showing that male students have superior logical thinking skills compared to female students [11]. Third, females are physically weaker than males [12], resulting in fewer females working in the field that requires strength, such as construction. Most of the students attributed their choices of liberal arts to cannot understanding scientific concepts and logic. The majority of them, as well as female students themselves, tended to associate female students with words such as perception, concentration, eloquence, and weak logic. There are preconceived perspectives about genders, that students intended to presuppose and label themselves by their genders. However, there are still a large proportion of students who believe that men and women have equal opportunities in major and career choices, indicating their growing awareness of gender equality.

From the interviews with parents, the conclusion can be drawn that the stereotype of boys being more capable of learning scientific subjects and girls being more suitable for liberal arts learning is commonly existing among most parents. Besides, this stereotype is groundless, with no reasoning supporting it. Also, from the questionnaire, it can be seen that the parents also have stereotypes about the future careers of boys and girls. Parents tend to believe that girls are born to be communicators or social workers rather than scientific researchers, admitting the potential impacts on their own children. This study believes the stereotype may directly change the education pattern of the students.

The most common answer the study got when asking the group Society about students' behavior at school is that girls perform well when they are young because they are more mature at that time, but boys will perform better when the students get older. Other stereotypical voices in the group Society the study got were: girls are not flexible when facing changes; girls are better at remembering details than following the logic. When asked about the future careers for each gender, the subjects in the group Society responded to the question under the gender stereotype that females should take more care of the husband, the children, and the family, showing the impact gender stereotypes have on the way people think [13].

\section{CONCLUSION}

The female students outnumbering the male students in foreign language school may be caused by the gender stereotypes held by different stakeholder groups (students, parents, and the society). The general stereotype existing in the society that girls perform well in liberal arts subjects whereas the boys are better in STEM courses shapes the education pattern adopted by students. The female students are more likely to attend foreign language schools not only because they are affected by the stereotype, but also because they are guided by their parents who also hold gender stereotypical views. Besides the stereotypes, objective differences of language learning in males and females also have an impact on girls' choices of studying at foreign language schools. Knowing the feminine advantages, such as brain structure, positive studying strategies, and motivation, in learning the language, girls are more willing to attend foreign language schools.

\section{REFERENCES}

[1] Lin, W. (2014). Multilingual curriculum and international understanding education. Journal of World Education, (18), 57-61.

[2] Hu, W. (2001). A matter of balance - reflections on China's language policy in education - Asian Englishes, 4(1), 66-79. DOI: https://doi.org/10.1080/13488678.2001.10801064.

[3] General Office of Ministry of education of the People's Republic of China (2007, November 30). The Notice for 2008 University Enrollment for Students with Foreign Languages Specialties. Ministry of education of the People's Republic of China. Retrieved October 9, 2021, from http://www.moe.gov.cn/srcsite/A15/moe_776/s325 8/200711/t20071130_79882.html.

[4] Ma, Liping, et al. (2016). Gender differences in college students' major choice. Journal of Lanzhou Institute of Education, (5), 36-42.

[5] Weng, Q. (2016). Analysis on the causes of professional gender segregation in Higher Education -- from the perspective of field theory. Journal of Higher Education, vol.34, no.1, pp.123-124,126.

[6] Burman, D. D., Bitan, T., \& Booth, J. R. (2008). Sex differences in neural processing of language among children. Neuropsychologia, 46(5), 1349 1362.

DOI: https://doi.org/10.1016/j.neuropsychologia.2007.12 .021 .

[7] Green, J. M., \& Oxford, R. (1995). A closer look at learning strategies, L2 proficiency, and gender. TESOL Quarterly, 29(2), 261. DOI: https://doi.org/10.2307/3587625.

[8] Mori, S., \& Gobel, P. (2006). Motivation and gender in the Japanese EFL classroom. System, 34(2), 194-210. DOI: https://doi.org/10.1016/j.system.2005.11.002.

[9] Heinzmanns, S. (2009). 'Girls are better at language learning than boys': Do stereotypic beliefs about language learning contribute to girls' higher motivation to learn English in primary 
school?. Swiss Association of Applied Linguistics, 89, 19-36.

[10] Hampson, E., Vananders, S., \& Mullin, L. (2006). A female advantage in the recognition of emotional facial expressions: Test of an evolutionary hypothesis. Evolution and Human Behavior, 27(6), 401-416.

https://doi.org/10.1016/j.evolhumbehav.2006.05.00 2.

[11] Manurung, S. R., \& Panggabean, D. D. (2018). The identification of logical thinking ability based on gender in physics teachers prospective students. Journal of Community Research and Service, 2(1), 192. https://doi.org/10.24114/jcrs.v2i1.10471.

[12] Björkqvist, K. (1994). Sex differences in physical, verbal, and indirect aggression: A review of recent research. Sex Roles, 30(3-4), 177-188. https://doi.org/10.1007/bf01420988.

[13] Ellemers, N. (2018). Gender stereotypes. Annual Review of Psychology, 69(1), 275-298. https://doi.org/10.1146/annurev-psych-122216-011 719. 